\title{
Algae Biofuel in the Nigerian Energy Context
}

\author{
Isa ELEGBEDE ${ }^{1 *}$, Cinthya GUERRERO \\ ${ }^{1}$ Department of Environmental Planning, Brandenburg University of Technology, Cottbus-Senftenberg, \\ Postfach 101344, 03013 Cottbus, Germany \\ ${ }^{2}$ Department of Power Plant Technology, Brandenburg University of Technology, Cottbus-Senftenberg, \\ Postfach 101344, 03013 Cottbus, Germany
}

\begin{abstract}
The issue of energy consumption is one of the issues that have significantly become recognized as an important topic of global discourse. Fossil fuels production reportedly experiencing a gradual depletion in the oil-producing nations of the world. Most studies have relatively focused on biofuel development and adoption, however, the awareness of a prospect in the commercial cultivation of algae having potential to create economic boost in Nigeria, inspired this research. This study aims at exploring the potential of the commercialization of a different but commonly found organism, algae, in Nigeria. Here, parameters such as; water quality, light, carbon, average temperature required for the growth of algae, and additional beneficial nutrients found in algae were analysed. A comparative cum qualitative review of analysis was used as the study made use of empirical findings on the work as well as the author's deductions. The research explored the cultivation of algae with the two major seasonal differences (i.e. rainy and dry) in Nigeria as a backdrop. The results indicated that there was no significant difference in the contribution of algae and other sources of biofuels as a necessity for bioenergy in Nigeria. However, for an effective sustainability of this prospect, adequate measures need to be put in place in form of funding, provision of an economically-enabling environment for the cultivation process as well as proper healthcare service in the face of possible health hazard from technological processes. Further studies can seek to expand on the potential of cultivating algae in the Harmattan season.
\end{abstract}

Keywords - Algae biofuel; Bioenergy; Algae cultivation; Renewable energy; Climate and Seasons

\section{INTRODUCTION}

Energy production has significantly evolved to become a global issue as it affects virtually every facet of human activities. Fossil fuels are the preponderant form of energy particularly in the oil-producing nations where activities of oil drilling have invariably created environmental hazards to man. These hazards and other reported negative impact of fossil fuel production underpins the study of the production of energy from a different, hazard-free context. Although various generations of alternative energy sources have been reviewed, adopted and developed by experts and stakeholders in different countries, there has been little or no commercial value made of alternative forms.

Energy sources are grouped into typology that can be placed into three subdivided forms namely categories A, B and C. Category A is the form of energy that has great economic ability and this type of energy source is transformed using high technological input. In category A, the hydropower, geothermal, nuclear are renewable energy while the fossil fuels are not renewable. Category $\mathrm{B}$ is a type of energy source does not have access to great economic consideration

\footnotetext{
* Corresponding author.

E-mail address: isaelegbede@gmail.com

(C)2016 Isa Elegbede, Cinthya Guerrero. This is an open access article licensed under the Creative Commons Attribution License

(http://creativecommons.org/licenses/by/4.0), in the manner agreed with De Gruyter Open.
} 
because of the conditions and irregularities of the sources. The unsustainable fuel wood are the non-renewable energy, while the Bio waste, Crop residues, windmills and watermills, including the sustainable fuel wood are the renewable form of energy. In Category $\mathrm{C}$, some of the sources of energy are highly sustainable. However, the petroleum oil, coal and gas are the nonrenewable energy sources while the solar, tidal and wave energy are the renewable forms of energy [1].

The distribution and utilization of the different energy sources are among the challenges facing the global energy balance systems on earth. The mismanagement and consumption of these energy sources, rivalry among oil-producing nations and rapid increase in population in some tropical regions of the world have affected the neutrality of the green earth. In addition, climate change is among the most challenging environmental issues with various consequences [1]. The most ravaging cause of climate change is from anthropogenic activities most especially uncontrolled and over usage of fossil fuel, which can be minimally caused by alterations in the biological, physical and chemical processes of the earth. Global warming is observed to be the most pronounced effect of climate change and it has been largely observed in the temperature rise of the earth between different centuries. These are caused by the anthropogenic manipulation of natural resources, therefore emitting greenhouse gases (GHG) namely, Nitrous oxide $\left(\mathrm{N}_{2} \mathrm{O}\right)$, Carbon dioxide $\left(\mathrm{CO}_{2}\right)$, Ozone $\left(\mathrm{O}_{3}\right)$, chlorofluorocarbon $(\mathrm{CFCs})$ and Methane $\left(\mathrm{CH}_{4}\right)$, which are majorly caused by fossil fuel. The effect of global warming has greatly affected the existence of human beings, irregular rainfall; reduction in global snow and natural ice; increase in temperature of daily cycles; global increment in ocean acidity and sea level rise [2]. Energy is a global necessity for sustenance. Some certain energy sources are subjected to end in the nearest future based on the projection of increasing human population and technological advancement [3]. However, this study evaluates the energy situation of Nigeria and the possibilities to incorporate algae biofuel in the energy mix of Nigeria to boost our renewable energy supply and consumption.

\section{OVERVIEW OF ENERGY AND BIOFUEL FOR NIGERIA}

\subsection{Global Energy Overview}

Energy consumption has significantly become one of the global issues that requires attention. Fossil fuels are considered as the most readily available energy source, uncertainty of its sustainability are yet to be resolved. Global energy production is envisaged to be at its peak in 2025 and 2050 respectively based on the (scenario) projection (Fig. 1.) that the population would increase, while production of fossil energy will gradually reduce [4]. The energy situation in most developing nations are unsatisfactory. About 3 billion individuals are deprived of effective energy services. They engaged their domestic activities with solid forms of energy including fossil fuels. Though, the under privileged people rely on fossil fuel at a greater cost, this cannot be fully relied upon because of the unproven and continuous emissions [5]. Over the years, efforts have been made by researchers to carry out studies on alternative means of energy sourcing and utilization, results have shown that algae biofuel is economically viable by both oil-producing and non-oil producing nations. Nigeria, being one of the oil rich nations in the world have also adopted and initiated programmes and policies on biofuel development.

Algae are a general nomenclature for organisms of photosynthetic origin. In nature, they exist at every geographical location of aquatic habitats, which include marine, brackish and freshwater environments. Algae are organisms with unique evolutionary trend, known to produce oxygen with size range of $0.2-2.0 \mu \mathrm{m}$ and $60.0 \mathrm{~m}$ length in diameter [3]. They exist on varieties of forms such as microscopic, macroscopic, unicellular, multicellular, simple and 
complex forms. Algae are majorly categorized into two parts namely, microalgae and macroalgae. Various forms of the species exist, with about 150,000 species of algae in existence [6].

\subsection{History of Algae Biofuel}

The laboratory culture and commercial cultivation of microalgae started in the late 1800 and mid 1900 respectively, with the culture of Haematococcus pluvialis (Chlorophyta) in 1850, Chlorococcum infusionum in 1871, Desmococcus olivaceus, Chlorella vulgarisin 1890 and diatoms in the late 1800 [7]. The proposal for algae as a green energy alternative and important gastronomy resources are due to its capacity to store high lipid content. Algae produce majorly lipid and protein, the lipid generated from algae is important for biofuel production. Beginning of the 1940s, extensive research on algae technology further continued in USA, Germany, Japan, England and Israel [7]. Extensive cultivation of microalgae production have been pioneered by Japan in the early 1960s by Nihon Chlorella with the culture of Chlorella spp. The use of algae for energy production also started in 1973 due to the inadequate supply of fossil fuel, which eventually became a crisis, although this was different from the motive to mitigate $\mathrm{CO}_{2}$ release. The research was funded by Exxon Research and Engineering Company [8].

In the USA, around 1978, a unique programme designed for algae production called Aquatic Species Program (ASP) was launched under the Department of Energy (DOE) with a financial commitment of US \$25 million. Afterwards the project was terminated due to inadequate funding in 1996 [9]. At the end of the ASP research, algae-derived biofuel was recognized as a promising and appreciable alternative pathway when compared to other biofuel programmes with great success in its biology, culture, biotechnological engineering and species categorization. A Japanese initiative on algae biofuel was also activated at a cost of US \$100 million but with little success. At late twentieth century, an organized extensive algae research facility was arranged in New Mexico and USA. These programmes reveal that reduced cost of production for algae derived biofuel is analytically feasible and later recommended that, there is need for more research to overcome the high productivity challenges [10]. In 2007, the global algae biomass production was around 10,000 tons, $50 \%$ of the production has been from China, while countries such as the USA, and some other nations including Australia also contributed to the remaining half percent [11].

\subsection{Algae Biofuels}

Generations are intervals of 30 years based on human definitions, technologically it is not the same. About $90 \%$ of the present biofuel consumed globally are from the first and second biofuel generations [12]. Due to the quality and quantity of feedstock, climate change including and technological considerations, algae biofuel generation is categorized into third and fourth biofuel generations.

First generation of biofuels are derived from food stuff biomass, such as vegetable, sugar, barley, potato wastes and oil producing plants [13]. The categories of biofuel produced are bioethanol and biodiesel. Countries such as Malaysia, Brazil, Germany and USA have successfully produced biofuels from palm oil, sugar cane, oilseed rape and corn respectively [14]. Due to sustainability concern, this category of biofuel have shown various limitations namely; inadequate fertile lands available for feedstock production, competition with edible food crops and water thereby increasing food prices. In addition, high overall production cost, reduced GHG emissions capacity, unsustainable production of feedstocks and contribution to deforestation thereby posing negative effect on biodiversity and the ecosystem [14], [15]. The second generation of biofuel is produced from non-edible dry plant matter called lignocelluloses biomass. It comprises carbohydrate and aromatic polymers, these categories of plants are mostly 
grown on non-arable crops. The lingo cellulosic feed stocks are non-edible with low economic importance, also include grass plant residues and waste including municipal non liquid waste [14]. These feedstocks are categorized into homogeneous (wood chips), quasi-homogeneous (agricultural and forest residues) and the non-homogeneous (solid waste), with average economic values of around $\$ 110 /$ ton, $\$ 62 /$ ton, $\$ 31 /$ ton respectively. This category of biofuel generation is obliged to proffer solution to the challenges of the first generation, particularly economic maximization and high-energy yield deficiency. There are still challenges in the areas of post-harvest loss and processing of the feed stocks to biofuel due to the complexities of the technology, which has been engaged by using either bio-pathway (isolation of the cellulose or lignin content) or thermo pathway (heating with oxidizing agent) [16], [17].

The biofuels generated includes bio hydrogen, wood, diesel, bio alcohol and bio-oil. The limitations attached are the tendency for a high production cost and low profit. The third generation of biofuel has been institutionalized to solve some of the problems of the old biofuel generations. The third generation of biofuel utilizes algae and microorganisms as a viable feedstock to produce biodiesel, jet biofuel, vegetable oil etc. These feedstock have the capacity to produce more oil for biofuel due to its short harvesting cycle of 5 days with high yield value than the arable and non-arable crops [6]. Carbon neutrality and reduction of non-anthropogenic carbon dioxide is one of the benefits of the third and fourth biofuel generations, a ton of algae biomass is capable to deplete about $163,293 \mathrm{~kg}$ of $\mathrm{CO}_{2}$ emissions. Algae biofuel production is highly advantageous compared to other biofuel product. $\mathrm{CO}_{2}$ is one of the major requirements of algae production, one ton of algae require about two tons of $\mathrm{CO}_{2}$, which is capable to produce about one ton of oxygen and successfully refine about 3.5 barrels of biodiesel [8], [18]. The fourth generation of biofuel adopts the use of Genetically Modified Microorganism (GMO) as feedstocks. It is aimed at capturing huge amounts of carbon from industrial process and power generation plants using coal as source of energy. These types of GMO species are manipulated to inhale $\mathrm{CO}_{2}$ to store lipid and energy for biofuel. This technology is mostly influenced by carbon storage and sequestration process [19]. The $\mathrm{CO}_{2}$ from various fossil operations can be a beneficial input for algae production. Some algae such as red algae (Chondria armata), green algae (Stichococus bacillaris), Chlorella vulgaris can absorb harmful hazardous metals, nitrogen oxides and sulphur oxides emissions [10], [35]. The enormous potential in the various algae species are positive indicators for biofuel production. The next section elaborates on the approach and the case study used.

\section{METHODS}

This research is an exploratory research that adopts opinions and views from different authors on the overall potential to contribute to algae biofuel production to the energy mix. Journals, maps, graphs as well as tables previously provided by authors on the significance of algae were all examined with the view to making informed deductions from the review. This was done by observing the growth of algae in both seasons with factors such as effect of rainfall, temperature etc. as studied.

\subsection{Study Case of Nigeria}

Nigeria, a tropical region situated along the western part of Africa is delineated as the site for the analysis of this study (Fig. 1.). It's seasonal period, particularly rain and dry with the third of it being the Harmattan. Nigeria has a great ration of yearly heavy rainfalls which invariably provide enabling environment for the continuous growth of algae. Nigeria is a tropical rich zone which lies between latitudes $4^{\circ} \mathrm{N}$ and $14^{\circ} \mathrm{N}$ and longitudes $2^{\circ} 2^{\prime} \mathrm{E}$ and $14^{\circ} 30^{\prime} \mathrm{E}$. It occupies a wide coverage of $923,770 \mathrm{~km}^{2}$ and about $853 \mathrm{~km}$ of coastline [20]. The country is endowed with 
hydrological potentials, considered as a great asset for the algae energy industry. The country's north-south extent is about $1,050 \mathrm{~km}$ and its east-west extent is about $1,150 \mathrm{~km}$, bordered to the west part by Benin Republic, to the north region by Niger and Chad. It is boarded in the east part of Cameroon [21]. The Nigerian climate is distributed evenly with tropical, arid, and equatorial seasons observed within the middle, north and the southern part of the country respectively [18].

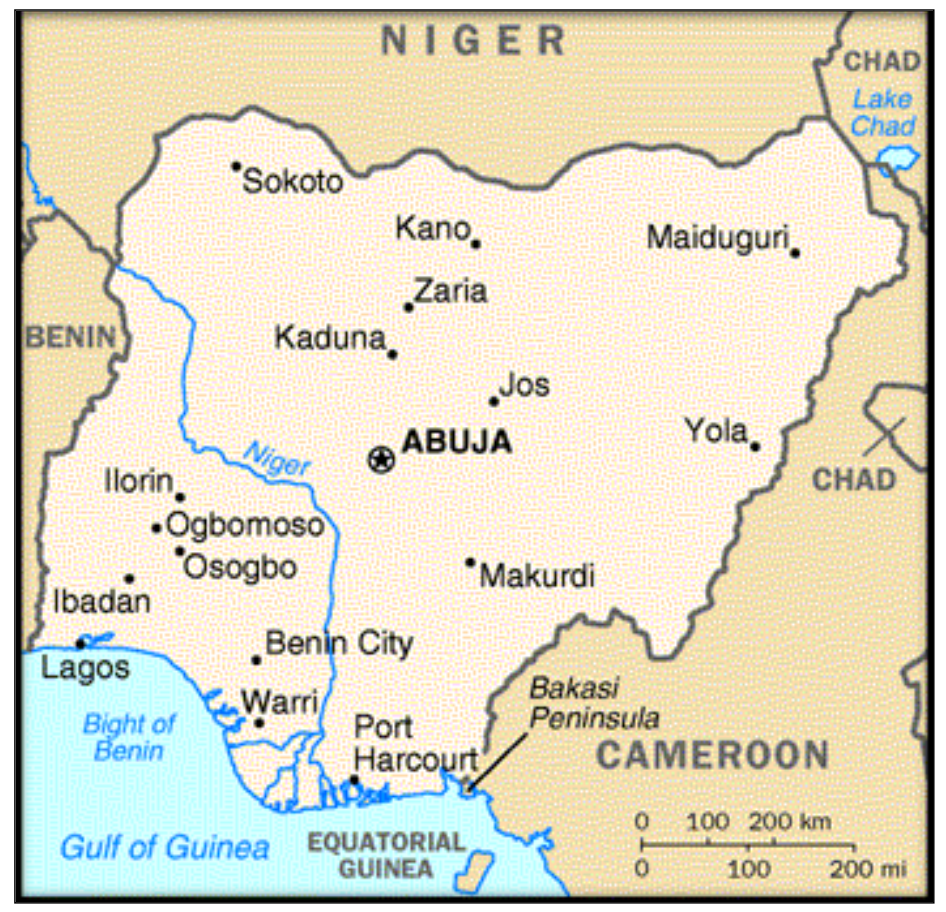

Fig. 1. Map of Nigeria showing geopolitical regions. [18]

\subsubsection{Energy mix of Nigeria}

Energy is a key tool for national development. In Nigeria, the need for energy consumption has been proven to be a recurrent menace that impedes the economic growth. Although there is preponderance of oil evidenced in the country's important ranking as the largest oil-producing nation in Africa and one of the biggest in the world, full utilization of these resources is yet to be achieved as a result of mismanagement. The major sources of energy in the country are the petroleum products, hydroelectricity, natural gas and fuel wood (biomass) [20]. Historically, algae which has not been adequately considered as capable of providing a much needed alternative in the area of biofuel production surprisingly has additional benefits to its utilization as it is also a source of lipid and protein concentrations.

Nigeria is ranked $19^{\text {th }}$ and $12^{\text {th }}$ position among energy and oil producing nations respectively, the country is yet to be independent in the refinery of its crude oil [16]. The country is also known for its large oil production ranking among the first fifteen largest oil producing countries in the world. This accounted for $96 \%$ of export earnings and more than $75 \%$ of federal government revenue in 2012. About $90 \%$ of the government income is sourced from overdependence on the oil sector, which has negatively affected other prospective energy generation sectors. The total primary energy produced, including petroleum, natural gas, coal, hydroelectric generation, nuclear, geothermal, solar, wind, wood, and waste electric power in 
2010 was 6.4 quadrillion. The highest oil production was observed in 2005 with values of 2,630 thousand barrels per day, which later dropped significantly in 2012 [22].

\subsubsection{Nigeria's biofuels}

In the Nigerian context, biofuel is defined as any fuel made from biological feedstock which is adopted for transportation, heat and power generation based on the Standards Organization of Nigeria (SON) and the Department of Petroleum Resources (DPR) [23]. In the global energy industry, fossil fuels are still available, but many countries have developed interest in renewable energy, most especially biofuel because of its $\mathrm{CO}_{2}$ mitigating potentials, and the concern to align with the motive of the Kyoto protocol, UNFCC and the United nation 2015 sustainable development goals. Nigeria has a high potential for biofuel production but due to existing fossil fuel volume, only few commitments is dwelled into biofuel, hence putting its biofuel status at the first and second generation.

Nigeria has earmarked cassava and sugar cane as good biofuel feedstocks. The renewable department of the Nigerian National Petroleum Corporation (NNPC) has confirmed the prospect of cassava and sugarcane for biofuel based on the need to diversify its energy resources. There is a possibility to earn about US $\$ 129$ million from biofuel investment, these have the potentials to promote the production of the crop plant output, and further enhance the implementation of the biofuel strategy. In line with this prospect, a total value of US \$92,000 grant have been received from Nigerian-German biofuel partnership initiative called Renewable Energy and Energy Efficiency Partnership (REEEP) [24]. The aim of this partnership is to reduce overdependence on fossil fuel and mitigate environmental pollution. The government also launched a biofuel initiative to identify industries that could create jobs and reduce the unemployment rate in the country. On a national scale, the benefits of the biofuel programme would generate income to the government, empowerment, economic growth, agricultural enhancement, synergistic energy benefit and greenhouse gas emissions [24].

The programme is structured into phases: the initial stage is the creation of the E-10 fuel type by a mixture of $10 \%$ ethanol biofuel and $90 \%$ gasoline. With the importation of ethanol biofuel, the produced biofuel is achieved in up to 10 years; simultaneous production of its feedstock production and biofuel refinery plants based on the anticipated $100 \%$ national production of consumed biofuel by 2020 [25]. The structure of the programme is directed to adopt the biofuel structure of Brazil, because the government of Brazil created enabling environment, incentive and accommodating policies, which is reflected in the success that is evident in her biofuel sector. Between 1975 and 2011, Brazil's biofuel production plant had expanded to over 400 stations with total biodiesel and bio-ethanol production of 600 million liters [26].

After the policy development of the Nigerian biofuels, about 24 projects are yet to be actualized, due to political and corruption issues in the country. Some progress have been confirmed such as installation and modification of biofuel handling facilities; confirmation of retail outlets for biofuel distribution; capacity building for personnel on biofuel quality and handling; standardized protocol for biofuel logistics; awareness of local farmers to cultivate biofuel crops. Biofuel progress in the county is not satisfactory although this is attributed to some impediments namely: lack of sustainability consideration of the initiative; political issues etc. The biofuel industry in Nigeria still depends on edible foodstuff, the increasing population is a challenge, because the available food is yet to be circulated among the people. A more proactive biofuel policy is needed in order to actualize all its aims. Also, the need to include algae as a third and fourth generation of biofuel in the Nigerian biofuel programme is important due to its prospects and importance on the Nigerian green economy [25]. 


\subsection{Data Analysis}

A qualitative analysis was used as the author examined different data available on the topic and made contributions to the review through judgments and opinions based on exploratory data analysis approach. Therefore, the author's findings are based on the judgment made from the inquiry into the review of the data sourced from the internet, journals, citations, maps, graphs and tables. The deductions made from this exploration which is the findings of the potential of cultivation of algae on a commercial scale as an alternative and sustainable source of energy consumption and production in Nigeria. Subsequent section explains the research findings with adequate discussion on other aspect of algae biofuel production.

\section{RESULTS AND DISCUSSION}

\subsection{Results}

Although an array of factors are considered responsible for the prospect of algae as an alternative means of energy production and consumption in Nigeria, some of the factors converge to bring the desired outcome of the research on this study to our understanding.

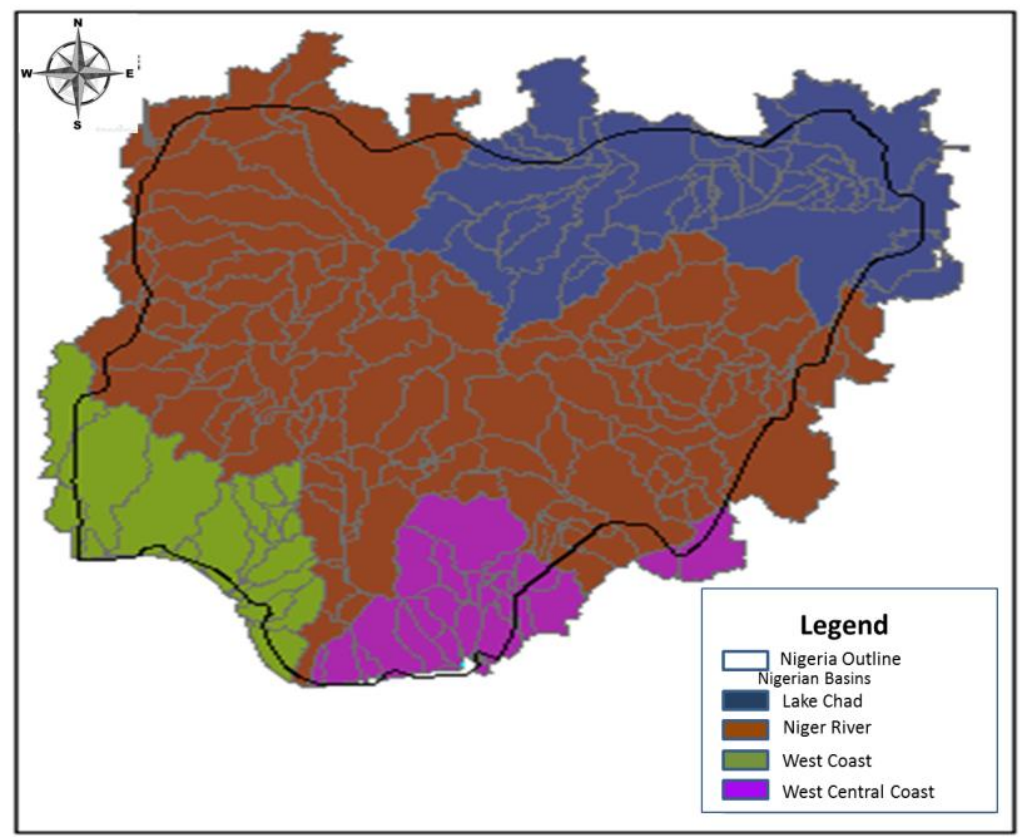

Fig. 2. Basins in Nigeria for water resources of algae production. [27]

Nigeria is a coastal region with boundaries along the southern area of the Atlantic Ocean. So, there is abundance in the availability of water, an important prerequisite for the growth of algae. 


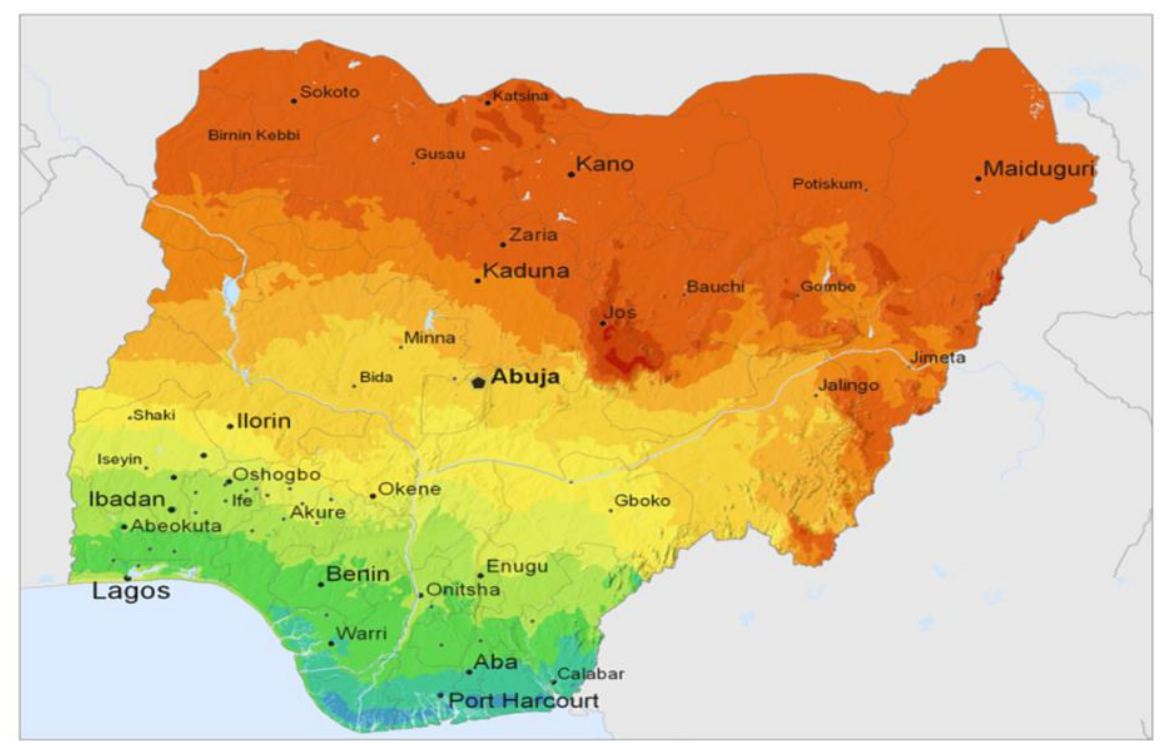

Average annual sum (4/2004 - 3/2010)

$<\begin{array}{llllll}800 & 1000 & 1200 & 1400 & 1600 & 1800>\mathrm{kWh} / \mathrm{m}^{2}\end{array}$

Fig. 3. Map of Nigeria showing radiation across regions. [28]

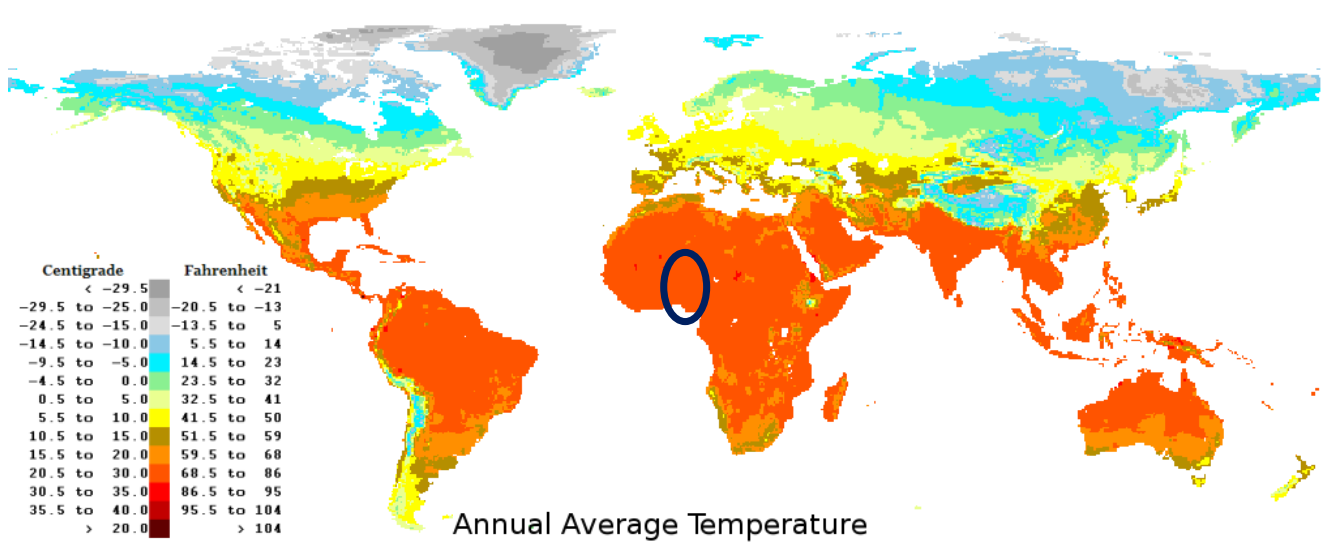

Fig. 4. Annual average temperatures of world zones scaled in Centigrade and Fahrenheit. [29] 


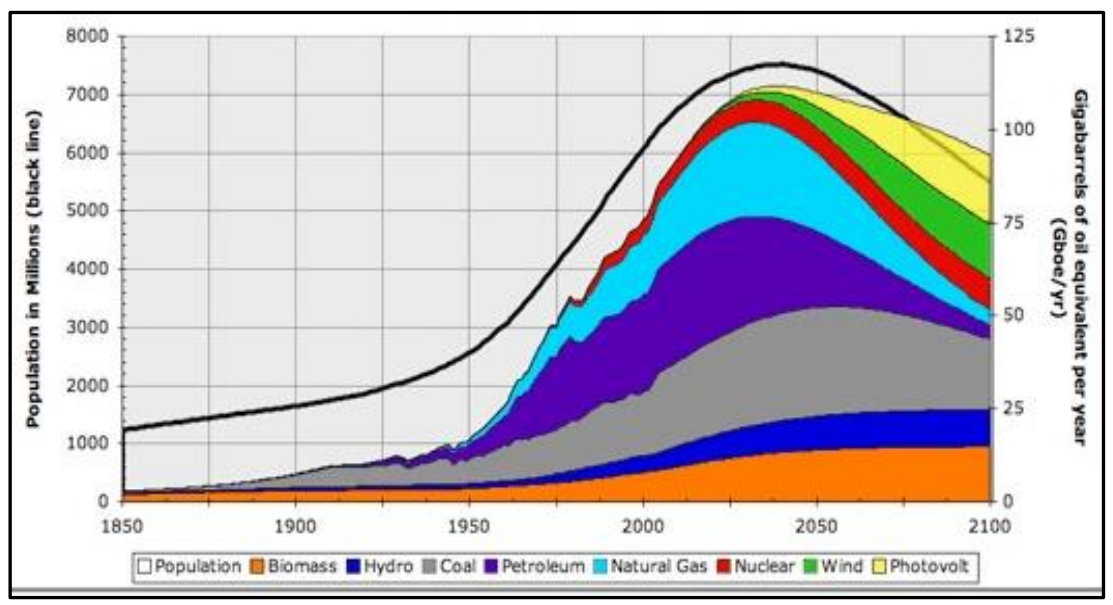

Fig. 5. World energy production. [3]

The graph illustrates assumptions of world energy production in proportion to population increase in the world from 1850 to 2100 .

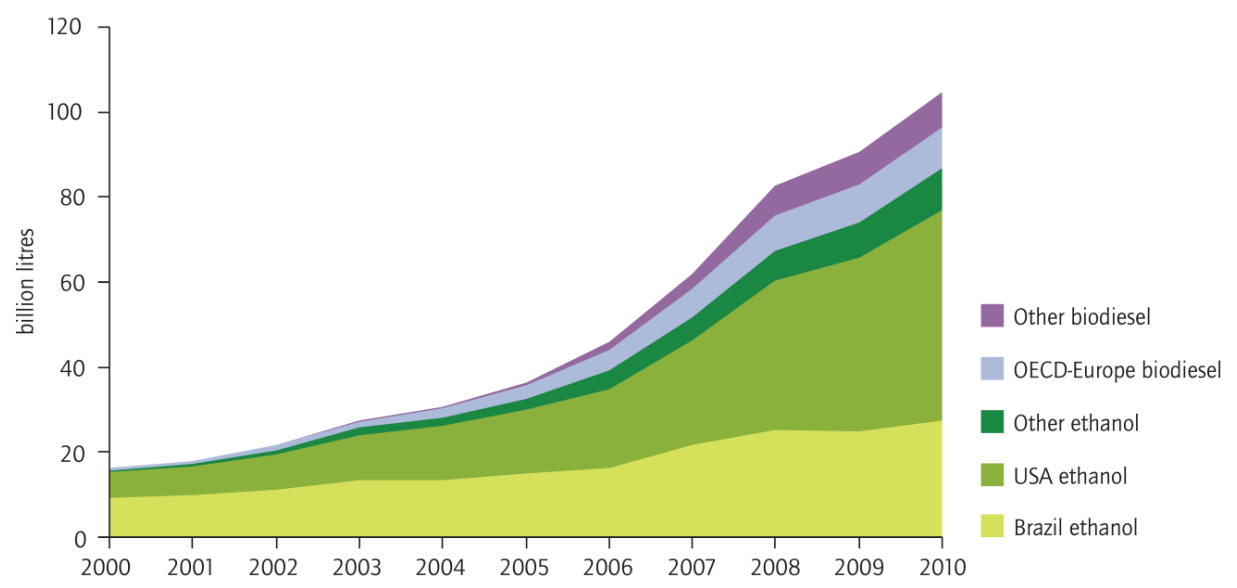

Fig. 6. World production of biofuel from 2000-2010. [30]

In a period of ten years, biofuel production has gradually increased in the world, which is an indicator of the awareness of the need to sustain energy consumption and production. Until 2010, biofuel production increased, and it is observed to further increase due to the awareness to mitigate Green House Gas (GHG) emissions particularly $\mathrm{CO}_{2}$. The implementation and localization of different policies and institutional framework, including capacity building are ongoing, which are affected by different funding from private and non-private institutions [30]. 


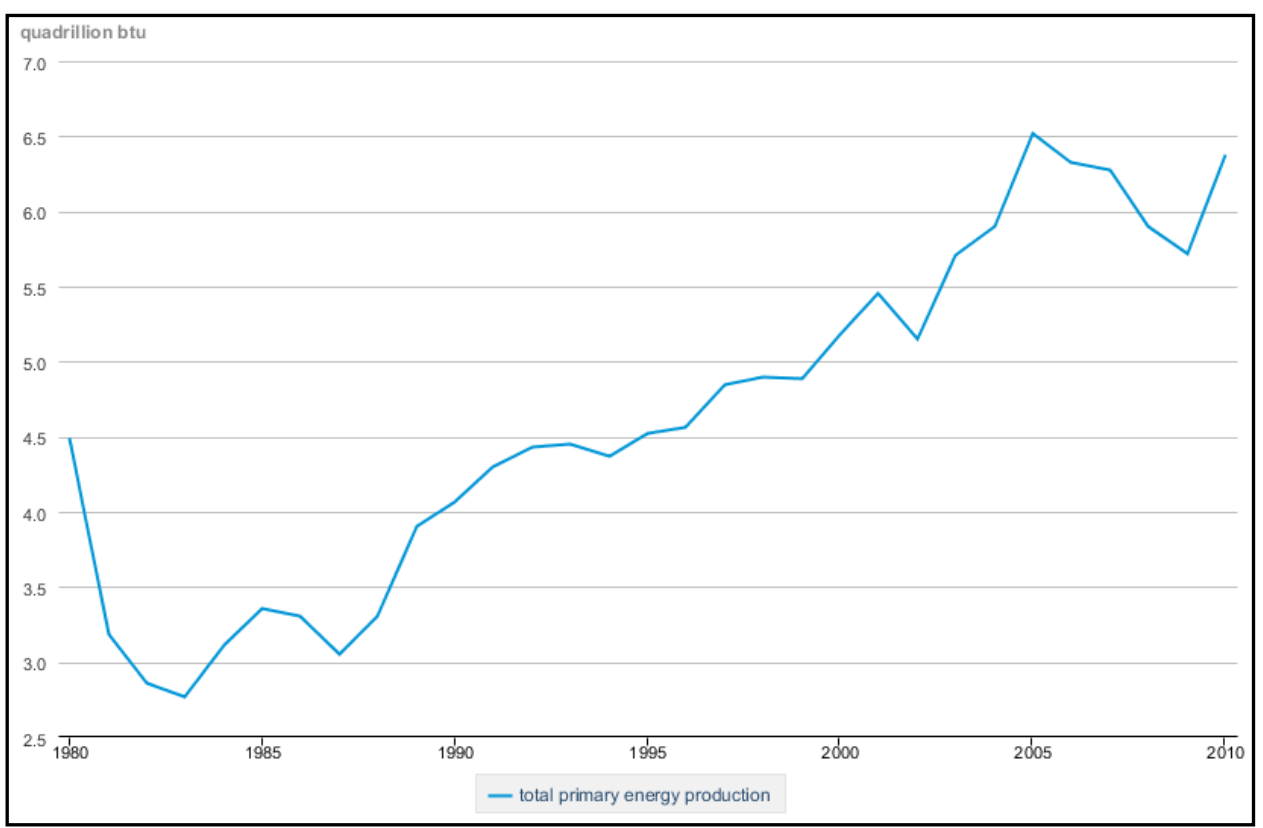

Fig. 7. Nigeria total primary energy production (1980-2010). [22]

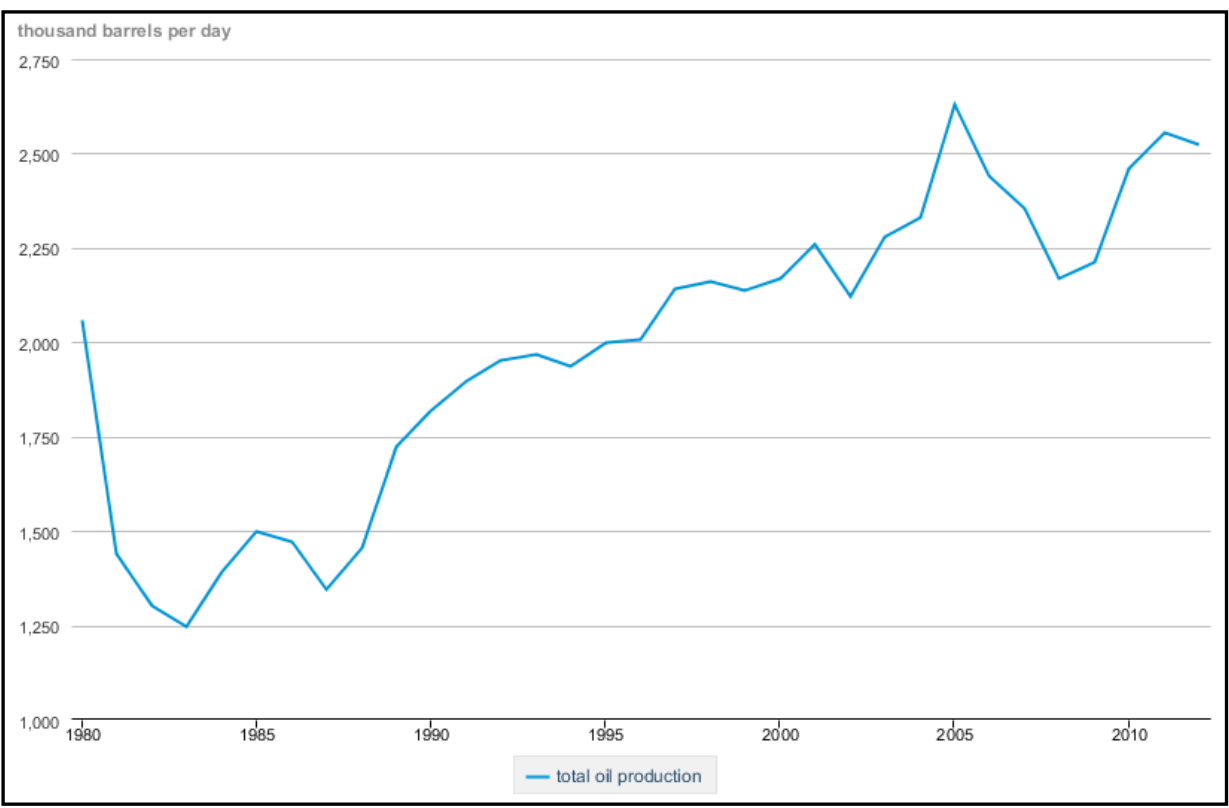

Fig. 8. Nigeria total oil production (1980-2012). [22]

A graph illustrating the values of oil production at an interval of 5 years. 

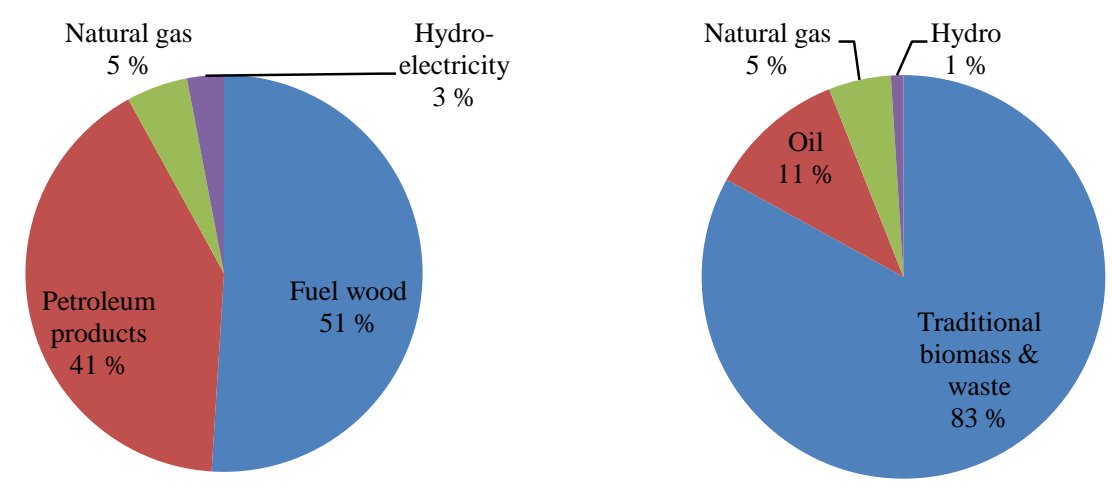

Fig. 9. The Nigeria energy mix. [20]

Fig. 10. Primary energy consumption and utilization of Nigeria. [22]

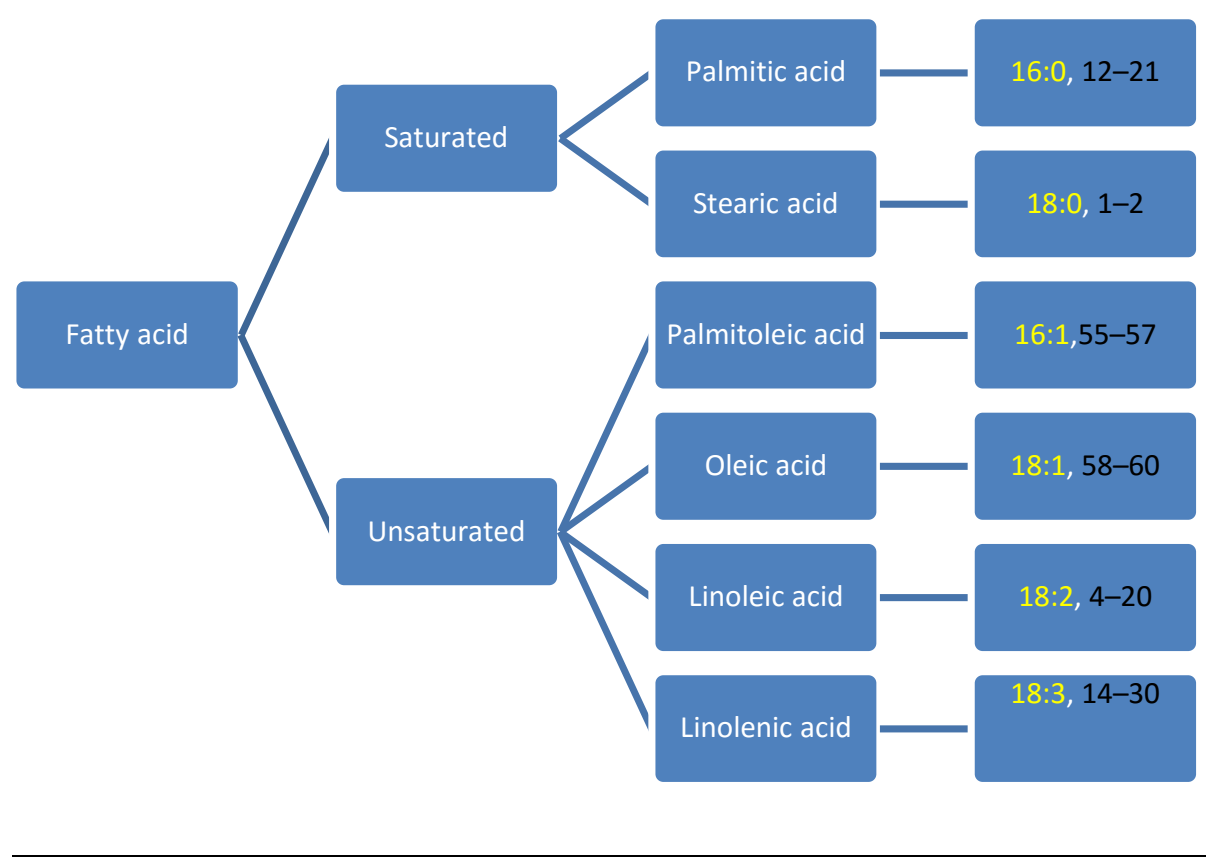

Note: Yellow colors are the chain length; Black colors are the oil constituent (without lipid).

Fig. 11. Fatty acid content of algae lipid. [23], [31]

The utilization of traditional biomass waste is an evidence that Nigeria already has a good use of biofuels as an alternative source of energy as it takes up the largest percentage of the primary energy consumption of the Nigerian populace reveals. This is revealed in the edge this utilization has over other forms, particularly with oil which is a major export commodity of Nigeria taking just meagre $11 \%$ of the primary. At $5 \%$, the natural gas contributes a least amount to the energy consumption in Nigeria, in spite of being an accompaniment of oil deposits. Hydropower ranks at the bottom of the energy consumption as it is used by the 
wealthiest class of Nigerians, usually by large scale enterprises and industries. Corroborating this analysis, people consume about $80 \%$ of fuel wood (traditional biomass and waste), $11 \%$ of oil product, $5 \%$ natural gas and $1 \%$ of hydroelectric power [13], [32].

Temperature is one of the most significant parameters for the growth of algae, the average temperature of the environment where the algae are cultivated. This is particularly favorable as a result of the advantage in the climatic condition of Nigeria where there is some amount of sunshine even in the dry season.

\subsection{Discussions}

Assessments of the parameters affecting the growth of algae, the geography of Nigeria, world energy production, the world's production of biofuels, the energy mix of Nigeria, the Nigerian energy consumption, the Nigerian energy production, with graphs, maps and charts as well as the contribution of the author's findings derived from different comparative analysis of data sourced are critical for the understanding of the growth of algae. In addition, fewer studies have been done on the utilization of algae cultivation as having a potential of creating a boom in the Nigerian economy. The knowledge of this is critical to the understanding of the significance of parameters measured in this study and other factors such as; ration of energy consumption to energy production in order to assist the government in making an inclusive but effective policy on the commercialization of algae cultivation as excellent alternative source of energy algae and other private sectors and other individuals in Nigeria.

\subsubsection{Effect of water, sunlight, temperature on the growth of algae}

Water is an integral requirement for the production of algae and it is abundance in Nigeria, it is also a merit for algae production and evidenced in the manner with which freshwater resources are strategically channeled all over the country (Fig. 2.). The quality of water required for the growth of algae is very favorable at large which mean it is an economically friendly business potential for anyone to venture into as the country has a network of associated rivers and streams across all its regions, namely Niger River, the Lake Chad, the West Coast, and the West Central Coast. The largest is the Niger River which occupies more than $60 \%$ of land [14], [30]. In the study of the requirements for mass cultivation of algae by, they require about $80 \%$ water of their weight, which is utilized for growth based on its photosynthetic nature [24]. One mole of water molecule is required for the process, which means that about $10 \mathrm{~kg}$ of water molecules are absorbed by a kilogram of algae. This is evident in the percentage of about $0.1 \%$ dry algae. These are highly dependent on the climatic conditions and the type of production systems available [17]. The NRC emphasizes the importance of water in algae production until the final process of the biofuel production is accomplished [28]. The importance of sunlight cannot be overemphasized as algae receive its first basic input from sunlight with a photosynthetic approach to convert radiation energy to algae biomass and eventually to the final biofuel product is Sunlight. Nigeria has abundant sunlight (Fig. 3.), which is a great requirement for algae production with annual average daily solar radiation of $3.5 \mathrm{kWh} / \mathrm{m}^{2}$ per day in the Southern region to $7 \mathrm{kWh} / \mathrm{m}^{2} /$ day in the northern arid region. The sunlight is particularly important for the photosynthetic activities of the algae. The photosynthesis process by algae affects biomass productivity, which is a function of light absorption and utilization, little amount of light is utilized by the species closer to the light, also they absorb more than those beneath. Excess light absorption result to oxidative damage which have been controlled by some mechanisms in the algae cell [33]. However, the result of the analysis of the radiation as studied in the map puts states in the northern region at an edge over the southern regions as the former fall within the $1800 \mathrm{kWh} / \mathrm{m}^{2}$ radiation. Algae production hinges on the average temperature experienced in the region where it is grown. Temperature zones vary in different continents as 
shown (Fig. 4.). $15^{\circ} \mathrm{C}$ of temperature or more is required for algae culture [2]. The temperature of Nigeria falls between $30^{\circ} \mathrm{C}$ and $35^{\circ} \mathrm{C}$, hence algae production for biofuel is a potentially fruitful venture for the Country. The annual temperature of algae production should be monitored in close relationship with optimum temperature required by the species and should be further confirmed based on different temperatures of the organisms. Subtropical algae strains are cultured with temperature of around $20^{\circ} \mathrm{C}$ and above; temperate algae strain maintains temperature of about $10{ }^{\circ} \mathrm{C}$. Averagely, the temperatures below $16^{\circ} \mathrm{C}$ will have a negative impact on the growth while temperatures higher than $35^{\circ} \mathrm{C}$ can denature and kill the algae biomass [3]. The effect of temperature generally did not impede the growth of algae, in both seasons as the least requirement of temperature for the growth of algae is available even during the rainy season in Nigeria.

\subsubsection{Ratio of energy production to the World Population}

The world population has been increasing at a geometric progression from 1850 to 2100 while biofuel production and utilization has seemingly been increasing at a much slower rate in most probably an arithmetic progression. With the assumption of the increase reaching a peak of about 7.5 billion, this peak would gradually plunge into a decline of about 5.5 billion by 2100 . The average global consumption of energy has witnessed average annual growth of $2 \%$ per year, as almost all the energy produced and consumed are from fossil energy. The biomass and hydrothermal energy production has been increasing at a slow rate due to the availability of other energy sources and because of its renewable nature and the prospect in its sustainability. However, coal, petroleum, nuclear and natural gas would attain their highest production values between the years 2025 and 2050 and suddenly decline because they are not renewable and are not sustainable. According to these assumptions, energy usage in some part of the world will continue to grow; this is an indication of the increase in the standard of living. The continuous surge as well as the projection in the world's population reveals the need to divert human efforts and resources to other more profitable source of energy. With the increase in the world's population disproportionate to the revenue generated by the government or the income earned by individuals, fossil fuels are fast dwindling, thereby precipitating the need for energy provision in a different context.

\subsubsection{Degree of the production of biofuels}

With the ever-increasing amount of population globally, especially in some countries in Asia, such as India and China, their economies are reportedly growing at a very rapid rate. Some countries are increasingly aware of the paucity and depletion in fossil fuels in the oil-producing nations and have been improvising various positive means of sustaining their energy consumption and production. Biofuels have long been discovered empirically to be a positive means of creating sustainability and countries have been utilizing biofuels. Countries ranking high in the production of biofuels are: USA, Brazil and some others in Europe (Fig. 6.). From year 2000 to 2010, the production of biofuels has increased significantly. There is an obvious awareness in the production and utilization of biofuels, particularly in the developed countries of Europe and in the some American countries. However, there is still not much done on the potential in the commercial production and consumption of algae cultivation.

\subsubsection{Irregularity/uncertainty in the energy and oil production in Nigeria}

Primary energy and oil production over the years have experienced irregularities at no particular order. Records revealed in (Fig. 7.), differential rates of the total primary energy production in Nigeria, experienced a positive starting point in 1980. At 4.5 quadrillion barrels, 
different decline and increase happened over the years until 2005 when a peak was attained at about 6.5 quadrillion. However, the subsequent years revealed decline and increase in no particular interval as well. Another indication of the uncertainty and irregularity in the oil production activity in Nigeria is revealed (Fig. 8.). With a quasi-promising start of production at a figure of 2050 barrels per day in 1980, a decline yet again fell in the year 83, rose again in 85 though it was below the production in 80 but declined again in 86 . It experienced a significant increase until 2005 when it reached its peak. Inversely, it declined again in subsequent years but increased in 2010 below the peak only to experience a major decline again in 2012.

The progression of energy and oil production to that of yearly progression is at a disproportion, an indicator for the necessity of alternative means of oil production which the cultivation of algae would solve to a very satisfactory extent. These are clear indicators for the necessity of a more stable, less-expensive and environmental-friendly means of energy production in Nigeria. Algae will continue to grow due to the presence of water, cultivating them on a commercial scale involves much lesser hazards compared to fossil production.

A critical look at the Nigeria Energy Mix as provided by Oyedepo [34]. Fuel wood takes a huge part of the source of energy in the category of biofuel in Nigeria. In spite of the hazardous effect of burning firewood, the accessibility and affordability of fuel wood to the average Nigerian makes it outnumber the percentage of energy gotten from petroleum products in the category of fossil fuels. Although a sizeable number of Nigerians focus and utilize other sources of bioenergy, particularly firewood as means of energy, the utilization and overdependence of petroleum products and fuel wood takes up too much of the energy mix in Nigeria. So, the place for algae as a source of biofuel to Nigeria is yet to be properly captured and explored in the biofuel utilization. Nigerians are yet to fully explore the economically-favorable merits as well as hazard-free option of algae biofuel as an excellent alternative source of energy in Nigeria.

The usage of fuel wood as a source of energy contributes the highest percentage to the energy mix of Nigeria (Fig. 9.). At $51 \%$, it outnumbers other forms of energy sources in Nigeria. Nigeria's energy consumption is related to its population, because inhabitants engage in transportation and domestic activities predominantly with fossil despite it being a hazardous means of environmental mitigation through the smoke/flames that are remnants of burning the wood during cooking or other human activities.

The petroleum products which are a major source of Nigeria's revenue lies behind the energy generated from fuel word. At $41 \%$, the petroleum products reveal the economic level of the average Nigerian who reportedly lives below a dollar per day. A clear indicator of the need to improve the standard of living of the Nigerian who might be willing to invest and/or embrace the utilization of algae cultivation as a source of biofuel is the large number of people utilizing fuel wood as a means of energy production. At $5 \%$, the energy sourced from natural gas contributes the least in Nigeria despite being a material gotten along with petroleum deposits. Ranking last at $3 \%$ is hydroelectricity which takes the lowest amount as it is expensive for the lower class.

\subsubsection{Potential for lipid and protein production, carbon offsetting and sequestration}

The lipid concentrations found in algae are also utilized in the pharmaceuticals and food industry. The six geopolitical zones in Nigeria are strategically situated to accommodate and provide environment-friendly conditions for the growth of algae, further indicated that the environmental status and the product of the environment affect lipid composition of algae [35]. They are climate change tool for carbon sequestration; hence, they can utilize the $\mathrm{CO}_{2}$ from industries for growth and production. They are toxic reducing agent; which can clean water to reduce unwanted particles. The following factors were found to impede the productive use of green energy: paucity of funding in form of grants from the private firms and the government in 
most of the developing countries, imbalance in the cost of green energy, inaccessibility to small markets with unavailability of credits, management incapability of renewable projects by financial institutions. All these could be resolved if financial institutions can satisfy a credible track record of activities there by leading to motivation for investors [36]. Some technological inputs are adopted such as carbon capture and storage, carbon offsetting etc. However, for an effective energy sustainability to be attained, factors such as environmental protection, renewable energy accessibility, cost effective energy price, health safeguards and security must be accomplished [35].

\section{CONCLUSiON}

This study investigated the potential of algae cultivation on a commercial scale as a necessity for bioenergy. The understanding of this study is significant for the qualitative planning and utilization of an environmental resource as well as a tool for economic diversification and expansion in Nigeria. The results revealed that there was no significant difference in the growth of algae in the dry season and the rainy season as a result of its readily rapid adaptive nature of growing in almost any kind of water and its abundant availability everywhere. However, it is true that as easy as it is to venture into algae cultivation for its potential as a source of biofuel production as well as usability in other significant industries, some measures have to be put in place by the government and other appropriate media of checks. Overall, algae have multiple beneficial merits to the energy consumption and production in Nigeria. There is need for the practice of cultivation of algae as an alternative means of sustainability of the energy sector in Nigeria. The Nigerian government needs to hit the ground running for people who are interested in this algae cultivation venture by creating an economically-enabling atmosphere as well as ensuring and enhancing participation and sponsorship from the private sectors especially the financial institutions and proper healthcare in the face of technological processes such as carbon capture and carbon offsetting. If all these measures are appropriately put in place, the energy sector would experience a surge in the economy/and then threat of the uncertainty in the continuous depletion of Nigerian's oil reserves, downward turn in the global oil pricing and greenhouse gas emission effect from drilling and burning of other biofuel sources. It is true that no research is exhaustive in and of itself so further studies on this topic can be done by exploring the growth of algae cultivation in the Harmattan, expanding on the parameters that were used in this study in order to broaden the expanse covered presently.

\section{ACKNOWLEDGEMENT}

As part of an ongoing research into the potential of algae cultivation on a commercial scale as a necessity for bioenergy. The authors wish to express profound gratitude for the immense contribution and assistance rendered by the Brandenburg University of Technology Cottbus-Senftenberg, Germany.

\section{REFERENCES}

[1] Akande S., Olorunfemi F. Renewable energy master plan for Nigeria: final draft report. African Research Review 2009:3(3):34-45.

[2] APEC. Resource Potential of Algae for Sustainable Biodiesel Production in the APEC Economies. USA and Australia. 2011. Available: http://www.biofuels.apec.org/pdfs/apec 201112 resource potential algae.pdf

[3] Barsanti L., Gualtieri P. Algae Anatomy, biochemistry, and biotechnology (Second Edition). Pisa: Taylor \& Francis Group, 2014.

[4] ICE. World Energy Production versus Consumption. 2008. Available: http://www.iceuls.com/present_energy_resources/world_energy_production_vs_consumption.php 
[5] Johansson T. B., Nakicenovic N., Patwardhan A., Gomez-Echeverri L. Global Energy Assessment (GEA)- Toward a sustainable Future. Laxenburg: Cambridge University Press, 2012. doi:10.1017/CBO9780511793677

[6] Guiry M., Guiry G. AlgaeBase. Available: http://www.algaebase.org

[7] Borowitzka M. A., Moheimani N. R. Algae for Biofuels and Energy. London: Springer Science, 2013. doi:10.1007/978-94-007-5479-9

[8] Chisti Y. Biodiesel from microalgae. Biotechnology Advances 2007:25(3):294-306. doi:10.1016/j.biotechadv.2007.02.001

[9] CIA. The world factbook 2013-14: Nigeria. Available: https:/www.cia.gov/library/publications/the-worldfactbook/geos/ni.html

[10] Climate Chart. World Climate Maps, 2007. Available: http://www.climate-charts.com/World-ClimateMaps.html\#temperature

[11] DOE, U. S. National Algal Biofuels Technology Roadmap. Maryland, 2010.

[12] Dragone G., Fernandes B., Vicente A. A., Teixeira J. A. Third generation biofuels from microalgae. Current Research and Education Topics in Applied Microbiology and Microbial Biotchnology. Formatex, 2010. Availbale: http://www.formatex.info/microbiology2/1355-1366.pdf

[13] EIA. (2013). Country Analysis Briefs. Nigeria. Retrieved Available: http://www.eia.gov/countries/country-data.cfm?fips=NI

[14] FAO. (2008). Water: Water profile of Nigeria. Encyclopedia of Earth. Available: http://www.eoearth.org/view/article/156977/

[15] Fay M. Biofuels Annual Report (Vol. 2012). Sao Paulo, 2013.

[16] Lee R. A., Lavoie J.-M. (2013). From first- to third-generation biofuels: Challenges of producing a commodity from a biomass of increasing complexity. Animal Frontiers 2013:3(2):6-11. doi:10.2527/af.2013-0010

[17] Sims R. E. H., Mabee W., Saddler J. N., Taylor, M. An overview of second generation biofuel technologies. Bioresource Technology 2010:101(6):1570-80. doi:10.1016/j.biortech.2009.11.046

[18] Kanes S., Forster D. The Choice of Next-Generation Biofuels ( Algae Excerpt ). 2009.

[19] IEA. World Energy Outlook 2010. Paris, 2010.

[20] Ladokun L. L., Ajao K. R., Sule B. F. Hydrokinetic energy conversion systems : prospects and challenges in Nigerian hydrological setting. Nigerian Journal of Technology 2013:32(3):538-549.

[21] IISD. A Citizens ' Guide To Energy Subsidies. Manitoba, Canada: The International Institute for Sustainable Development, 2012.

[22] Mata T. M., Martins A. A., Caetano N. S. Microalgae for biodiesel production and other applications: A review. Renewable and Sustainable Energy Reviews 2010:14(1):217-232. doi:10.1016/j.rser.2009.07.020

[23] Meng X., Yang J., Xu X., Zhang L., Nie Q., Xian M. (2009). Biodiesel production from oleaginous microorganisms. Renewable Energy 2009:34(1):1-5. doi:10.1016/j.renene.2008.04.014

[24] Murphy C. F., Allen D. T. Energy-water nexus for mass cultivation of algae. Environmental Science \& Technology 2011:45(13):5861-8. doi:10.1021/es200109z

[25] NNPC. Federal Republic of Nigeria Official Gazette of the Nigerian Bio-fuel Policy and Incentives NIGERIAN BIO - FUEL POLICY INCENTIVES. Abuja, Nigeria: 2007.

[26] Nkwunonwo U. C., Okeke F. I. GIS-based production of digital soil map for Nigeria. Ethiopian Journal of Environmental Studies and Management 2013:6(5):498-506. doi:10.4314/ejesm.v6i5.7

[27] NRC. Advancing the Science of Climate Change. Washington, DC: The National Academies Press, 2010.

[28] NRC. Sustainable Development of Algal Biofuels in the United States. Washignton, DC: 2012.

[29] Ohimain E. I. Can the Nigerian biofuel policy and incentives (2007) transform Nigeria into a biofuel economy? Energy Policy 2013:54:352-359. doi:10.1016/j.enpol.2012.11.051

[30] Oshodi K. S. Hydrological Study of Nigeria GIS Term Project. 2005. Available: http://www.crwr.utexas.edu/gis/gishydro06/Introduction/TermProjects/OSHODI-GISHYDRO.htm

[31] Singh A., Nigam P. S., Murphy J. D. Mechanism and challenges in commercialisation of algal biofuels. Bioresource Technology 2011:102(1):26-34. doi:10.1016/j.biortech.2010.06.057

[32] Vincent-Akpu I. Renewable energy potentials in Nigeria University of Stirling. Presented at Energy Future The Role of Impact Assessment 32nd Annual Meeting of the International Association for Impact Assessment. Centro de Congresso da Alfândega, Porto, Portugal, 2012.

[33] SOLARIS. (2011). Direct normal radiation Nigeria. Available: http://solargis.info/doc/_pics/freemaps/1000px/dni/SolarGIS-Solar-map-DNI-Nigeria-en.png

[34] Oyedepo S. O. Energy in Perspective of Sustainable Development in Nigeria. Sustainable Energy 2013:1(2):14-25.

[35] Wu X., Ruan R., Du S., Liu Y. Current Status and Prospects of Biodiesel Production from Microalgae. Advances in biofuel production: Algae and Aquatic Plants (Second edition). Apple Academic Press, 2014. 
[36] Williams P. J. L. B., Laurens L. M. L. Microalgae as biodiesel \& biomass feedstocks: Review \& analysis of the biochemistry, energetics \& economics. Energy \& Environmental Science 2010:3(5):554. doi:10.1039/b924978h

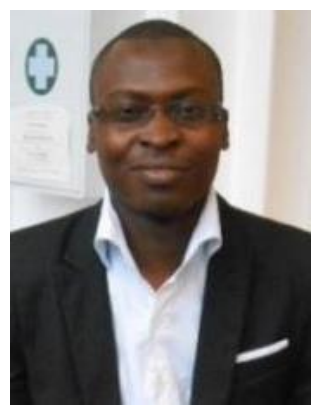

Elegbede, Isa Olalekan received the BSc degree in fisheries from the Lagos State University, Ojo, Nigeria, also proceeded further to earn the M.Sc. in marine sciences (marine pollution and management), at the University of Lagos, Akoka, Nigeria. He also earned a second M.Sc. in Environmental and resource management at the Brandenburg University of Technology, Cottbus-Senftenberg, Germany. He is presently a $\mathrm{PhD}$ researcher in environmental and resource management at the department of environmental planning, Brandenburg University of Technology, Cottbus-Senftenberg, Germany. He has membership status in the following professional societies: American Fisheries Society, USA (AFS), Association for the Science of Limnology and Oceanography, Texas, USA (ASLO), Friends of the Earth, Germany (Bund fur Umwelt und Naturschutz, Deutschland), International Society of Sustainability Professionals (ISSP)

Email: isaelegbedemail.com; ORCID: orcid.org/0000-0002-8794-8616. 